\title{
Interacting Blends of Novel Unsaturated Polyester Amide Resin with Vinyl Acetate
}

\author{
H. S. PATEL,* K. K. PANCHAL, S. R. PATEL and S. N. DESAI \\ Department of Chemistry, Sardar Patel University, \\ Vallabh Vidyanagar-388 120, Gujarat (India).
}

Received 31 June 2004; Accepted 10 Sep 2004

\begin{abstract}
Novel unsaturated poly (ester- amide) resins (UPEAs) were prepared by the reaction between an epoxy resin, namely diglycidyl ether of bisphenol-A (DGEBA) and unsaturated aliphatic bisamic acids using a base catalyst. These UPEAs were then blended with a vinyl monomer namely, Vinyl acetate (VA) to produce a homogeneous resin syrup. The curing of these UPEAs-VA resin blends was carried out by using benzoyl peroxide (BPO) as an initiator for the radical polymerization and was monitored by using a differential scanning calorimeter (DSC). The glass fibre reinforced composites (i.e. laminates) of these UPEA-VA resin blends were fabricated using the DSC data. The chemical, mechanical and electrical properties of the glass fibre composites have also been evaluated. The unreinforced cured samples of the UPEA-VA resin blends were also analyzed by thermogravimetry (TGA).
\end{abstract}

Key words Unsaturated poly (ester-amide), Interacting polymer blends, DSC, Glass fibre reinforced composites

\section{Introduction}

Polyester and polyamide resins are manufactured industrially for a number of applications. ${ }^{1-6}$ By blending or copolymerising somew hat hydrophilic polyamide and hydrophobic polyesters products can be made that could find a variety of applications. The so-called poly (ester-amide) resins are almost saturated. $^{7-12}$ Poly (ester-amide) resins with unsaturated segments have received very little attention academically or industrially. ${ }^{13}$ The introduction of unsaturation, amide and ester groups into one polymer chain may afford polymers having a cross-linking capability with vinyl monomers. Recently the present authors have reported novel unsaturated poly (ester-amide) resins synthesized by using epoxy resins. ${ }^{14}$ Unsaturation in such poly (ester-amide) resins interacts with the vinyl monomer to form a blend. Hence it was thought interesting to study interacting blends of unsaturated poly (ester-amide) with the vinyl monomers. So the present communication describes interacting blends of unsaturated poly (ester-amide) with vinyl acetate as shown in Scheme-1.

\section{Experimental}

Materials

Commercial epoxy resin, diglycidyl ether of bisphenol-A (DGEBA) was obtained from Synpol Products Ltd. The grade characteristics were;

- Epoxy equivalent weight - 190,

- Viscosity - 9000 to $12000 \mathrm{mPas}$ at $25^{\circ} \mathrm{C}$,

- Density at $25^{\circ} \mathrm{C}-1.16-1.17 \mathrm{~g} . \mathrm{cm}^{-1}$. 


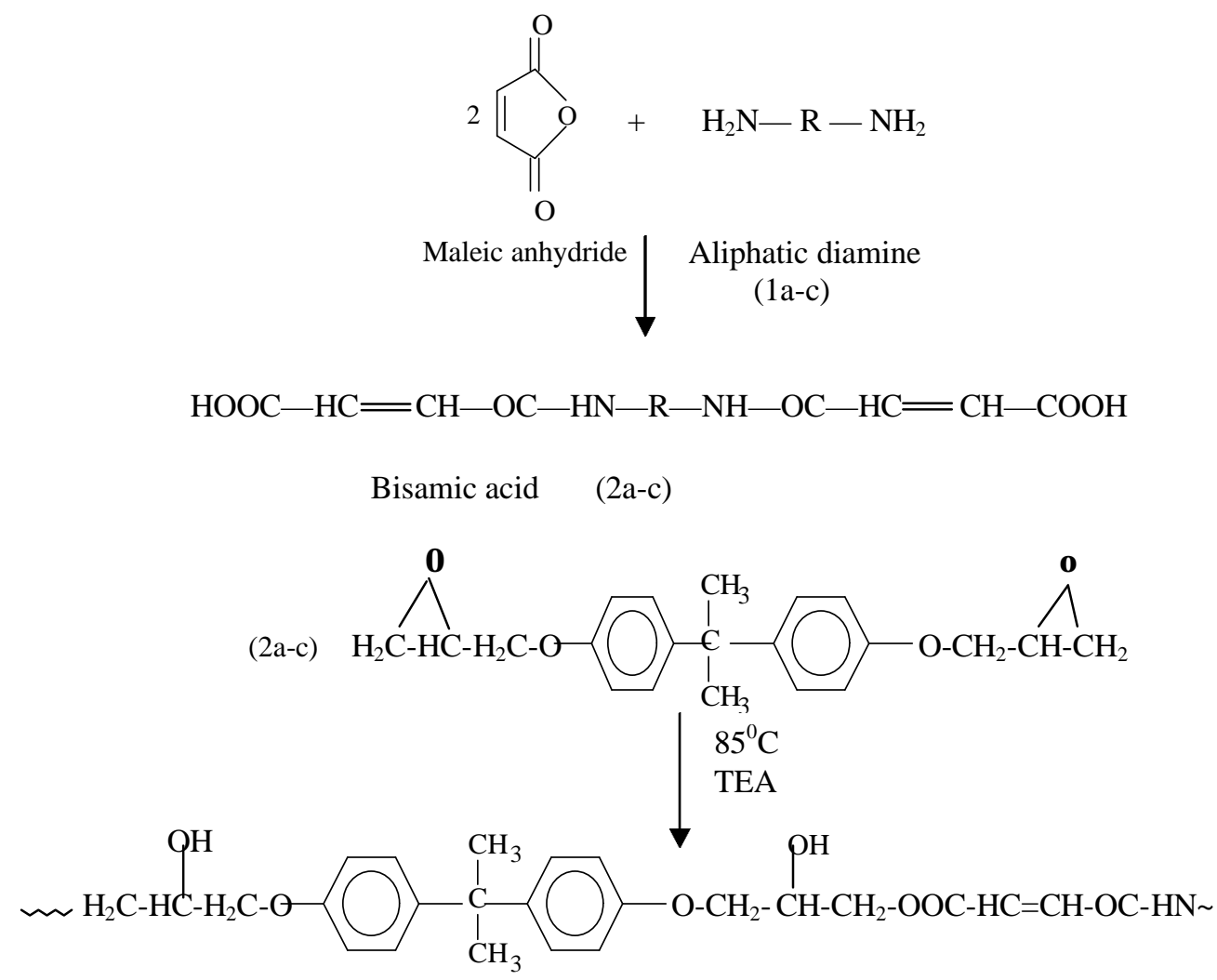

Unsaturated polyesteramide $(3 a-c)$
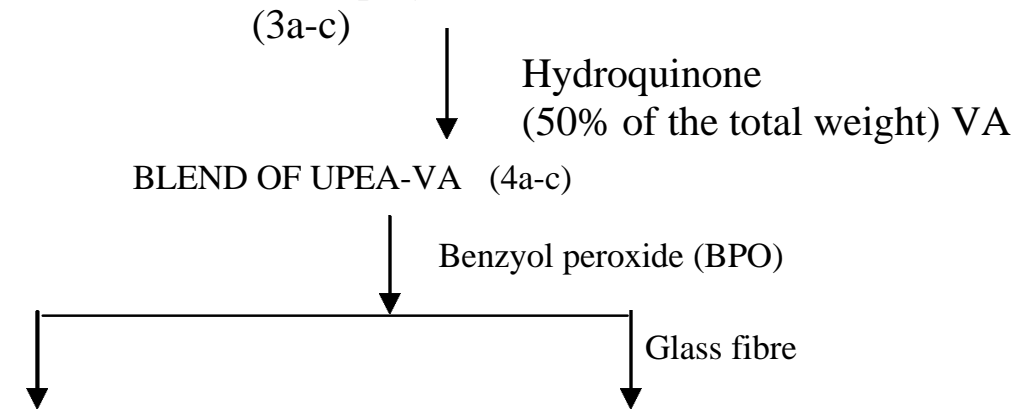

Cured product

Glass fibre reinforced composites.

Where $\mathrm{R}=(\mathrm{a})-\left(\mathrm{CH}_{2}\right)_{2^{-}} \quad$ (b) $-\left(\mathrm{CH}_{2}\right)_{3^{-}} \quad$ (c) $-\left(\mathrm{CH}_{2}\right)_{6^{-}}$

Scheme - 1 
The aliphatic diamines used for the synthesis of unsaturated bisamic acids were;

1. 1,2-Ethane diamine,

2. 1,3-Propane diamine, and

3. 1,6-Hexamethylene diamine.

These diamines were obtained from Diamines Chemicals, Nandesari. The Glass fibres used for composites fabrication were obtained from Unnati Chemicals, Ahmedabad and were of E-type glass cloth, plain weave and epoxy/vinyl compatible. All the other chemicals used were of laboratory grade.

Synthesis of Unsaturated Bisamic acids:

All the three unsaturated bisamic acids were prepared by a simple condensation reaction between maleic anhydride and the aliphatic diamines, following the method reported in the literature. ${ }^{9-10}$ All the three-bisamic acids (now designated as unsaturated bisamic acids) (2a-c) were obtained in pow der form and their structures are show $n$ in Scheme - 1.

Synthesis of Unsaturated poly (ester -amide) resins (UPEA):

The three unsaturated poly (ester-amide) (UPEA) resins were prepared by the method reported in our earlier communication. ${ }^{14}$ These UPEAs were designated as (3a-c). Epoxy resin i.e. DGEBA (1.1mole) and unsaturated bisamic acid (2a-c) were charged into a three necked flask equipped with a mechanical stirrer. To this, tri ethyl amine (8.3\%) of the total weight of the above was added as a catalyst. The mixture was heated to $85^{\circ} \mathrm{C}$ with continuous stirring. Samples were taken at regular intervals to check the acid value. The reaction was carried out until the acid value fell below $55 \mathrm{mgKOH} / \mathrm{gm}$ and then the resin was discharged to give unsaturated poly (ester-amide) resin (UPEA) (3a-c)

Synthesis of interacting blends of unsaturated poly (ester -amide) with Vinyl acetate monomer: $0.01 \%$ of the total weight of UPEA (3a-c), hydroquinone was added as an inhibitor and stirred well for a few minutes while maintaining the temperature at $85^{\circ} \mathrm{C}$. After this vinyl acetate monomer $(50 \%$ of the total weight of the above), was added. Then the temperature was lowered to $80^{\circ} \mathrm{C}$ and the whole mixture was continuously stirred for 1 hour at $80^{\circ} \mathrm{C}$. This gave a viscous resinous blend of unsaturated poly (ester- amide) vinyl acetate resin. All the three blends (4a-c) were obtained in the form of viscous resinous syrup.

Synthesis of cured interacting UPEA-VA Blends:

The interacting UPEA-VA resin blends (4a-c) along with benzoyl peroxide as a catalyst were heated in a conical flask at their respective peak temperatures obtained from the DSC thermograms. The resulting solid material was designated as unreinforced material, which is so fragile that it can be crushed even by hand pressure.

\section{Composite Fabrication}

The composites were prepared using glass fibres with a glass fibre: resin ratio of 60:40. $0.05 \%$ benzoyl peroxide (BPO) based on the total weight of the UPEA-VA resin blends (4a-c), was added as an initiator. This syrup was well stirred for about $5 \mathrm{~min}$. The syrup was then applied to a $150 \mathrm{~mm} \times 150 \mathrm{~mm}$ glass fibre ply. The prepregs plies were stacked on top of one another and pressed between steel plates coated with a Teflon film release sheet and compressed in a flat platen under 70 psi pressure. Keeping it in an autoclave oven maintained at their respective curing temperatures for about 6 hours cured this prepregs stack. The composites obtained were cooled to $50^{\circ} \mathrm{C}$ before the pressure was released. They were then machined to final dimensions.

\section{MEASUREMENTS}

Curing:

A curing study of all the UPEAs-VA resin blends (4a-c) was carried out by using benzoyl peroxide as an initiator as described and was monitored by differential scanning calorimeter (DSC). A Du Pont High pressure 990 DSC thermal analyzer was used for this study. The instrument was calibrated using standard indium metals with a known heats of fusion $(\Delta \mathrm{H}=28.45 \mathrm{~J} / \mathrm{g})$. Curing was carried out from $30-$ 
$300{ }^{\circ} \mathrm{C}$ at $10{ }^{\circ} \mathrm{C} \mathrm{min}^{-1}$ heating rate. The sample weight for this investigation was in the range of 4-5 $\mathrm{mg}$ and an empty cell was used as a reference. The DSC thermograms data are furnished in Table 1. Unreinforced cured blend samples were subjected to thermo gravimetric analysis (TGA) on Du Pont 990 thermal analyzer MK III, in air at a heating rate of $10^{\circ} \mathrm{C} \mathrm{min}^{-1}$. The TGA data are furnished in Table 2 .

\section{Composite Characterization}

Chemical resistance test:

The resistances against chemicals of the composite were measured according to ASTM D 543. The specimen dimensions were $20 \mathrm{~mm} \times 20 \mathrm{~mm}$. The chemicals used for the study were $\mathrm{H} 2 \mathrm{SO} 4(25 \% \mathrm{v} / \mathrm{v}), \mathrm{HC}$ $(25 \% \mathrm{v} / \mathrm{v}), \mathrm{NaOH}(25 \% \mathrm{w} / \mathrm{v})$ ethanol, acetone, THF and DMF.The test was performed by dipping the composite sample in $100 \mathrm{ml}$ each of the above reagents for 7 days at room temperature. After 7 days the specimens were taken out from the reagents and after drying they were examined for the percentage change in thickness and weight. Their results are furnished in Table-3.

Mechanical testing:

All mechanical testing were performed using three test specimens are their average results are furnished in Table-4.

- The compressive strength was measured on a Universal Instron testing machine of model no. a-74-37 at room temperature according to ASTM D 695.

- $\quad$ Notched Izod impact strength was measured on a Zwick model no. 8900 impact tester machine at room temperature, according to method of ASTM D 256.

- The Rockwell hardness was measured on a Rockwell hardness tester model RAS/Saro Engg. Pvt. Ltd. At room temperature according to ASTM D 785.

Electrical testing:

The measurement of the dielectric strength was carried out on a high voltage tester machine oil test set.

Table -1 DSC Curing of Blend of Unsaturated Polyester amide- Vinyl acetate Resins. (UPEA-VA).

\begin{tabular}{|c|c|c|c|}
\hline \multirow{2}{*}{ UPEA-VA Sample } & \multicolumn{3}{|c|}{ Curing Temp. $\left(\mathrm{T}^{0} \mathrm{C}\right)$} \\
\cline { 2 - 4 } & $\begin{array}{c}\text { Cure Onset } \\
\text { Temp. }\left(\mathrm{T}_{\mathrm{i}}\right)\end{array}$ & $\begin{array}{c}\text { Peak Cure } \\
\text { Temp. }\left(\mathrm{T}_{\mathrm{p}}\right)\end{array}$ & $\begin{array}{c}\text { Final Cure } \\
\text { Temp. }\left(\mathrm{T}_{\mathrm{f}}\right)\end{array}$ \\
\hline $4 \mathrm{a}$ & 88 & 131 & 153 \\
\hline $4 \mathrm{~b}$ & 92 & 135 & 157 \\
\hline $4 \mathrm{c}$ & 96 & 139 & 161 \\
\hline
\end{tabular}

Table -2 TGA of unreinforced cured sample of UPEA-VA resin bends

\begin{tabular}{|c|c|c|c|c|c|}
\hline \multirow{2}{*}{$\begin{array}{c}\text { UPEA-VA } \\
\text { Sample }\end{array}$} & \multicolumn{5}{|c|}{ \% Weight loss at various Temp. $\left({ }^{\circ} \mathrm{C}\right)$ From TGA } \\
\cline { 2 - 6 } & 150 & 300 & 450 & 600 & 750 \\
\hline $4 \mathrm{a}$ & 3.18 & 10.98 & 75.80 & 82.34 & 86.96 \\
\hline $4 \mathrm{~b}$ & 3.21 & 9.76 & 75.10 & 81.96 & 85.80 \\
\hline $4 \mathrm{c}$ & 3.25 & 9.70 & 74.76 & 81.04 & 84.62 \\
\hline
\end{tabular}


Table -3 Chemical properties of glass fibre reinforced composites of UPEA-VA Resin blends.

\begin{tabular}{|c|c|c|c|c|c|c|}
\hline $\begin{array}{c}\text { Resin } \\
\text { system }\end{array}$ & \multicolumn{2}{|c|}{$\begin{array}{c}4 a \\
\text { \% Change in }\end{array}$} & \multicolumn{2}{c|}{$\begin{array}{c}\text { 4b } \\
\% \text { Change in }\end{array}$} & \multicolumn{2}{c|}{$\begin{array}{c}4 c \\
\% \text { Change in }\end{array}$} \\
\hline Reagents & Thickness & Weight & Thickness & Weight & Thickness & Weight \\
\hline $25 \% \mathrm{H} 2 \mathrm{SO} 4$ & 1.20 & 1.90 & 1.18 & 1.85 & 1.22 & 1.92 \\
\hline $25 \% \mathrm{HC}$ & 0.85 & 1.57 & 0.80 & 1.49 & 0.82 & 1.53 \\
\hline $25 \% \mathrm{NaOH}$ & 0.98 & 1.62 & 1.02 & 1.71 & 1.09 & 1.76 \\
\hline Ethanol & 0.26 & 0.36 & 0.29 & 0.31 & 0.32 & 0.39 \\
\hline Acetone & 0.21 & 0.32 & 0.18 & 0.28 & 0.25 & 0.36 \\
\hline DMF & 1.25 & 2.05 & 1.31 & 2.10 & 1.29 & 2.07 \\
\hline THF & 0.56 & 0.77 & 0.61 & 0.87 & 0.64 & 0.89 \\
\hline
\end{tabular}

Table-4 Mechanical and Electrical properties of glass fibre reinforced composites of blends of UPEA-VA resins.

\begin{tabular}{|c|c|c|c|c|}
\hline $\begin{array}{c}\text { UPEA-VA } \\
\text { Composite } \\
\text { samples }\end{array}$ & $\begin{array}{c}\text { Impact } \\
\text { strength } \\
(\mathrm{Mpa})\end{array}$ & $\begin{array}{c}\text { Compressive } \\
\text { strength } \\
(\mathrm{MPa})\end{array}$ & $\begin{array}{c}\text { Rockwell } \\
\text { hardness } \\
(\mathrm{R})\end{array}$ & $\begin{array}{c}\text { Electrical } \\
\text { strength in air } \\
(\mathrm{kV} / \mathrm{mm})\end{array}$ \\
\hline $4 \mathrm{a}$ & 405 & 410 & 86 & 22.12 \\
\hline $4 \mathrm{~b}$ & 422 & 402 & 90 & 24.15 \\
\hline $4 \mathrm{c}$ & 434 & 392 & 95 & 25.80 \\
\hline
\end{tabular}

Conditions reinforcement; E type glass cloth, plain w eave, eight layers; resin content: 40\%; curing time: $6 \mathrm{hr} . ;$ curing pressure $70 \mathrm{psi}$;

DSC Thermogram of UPEA-VA

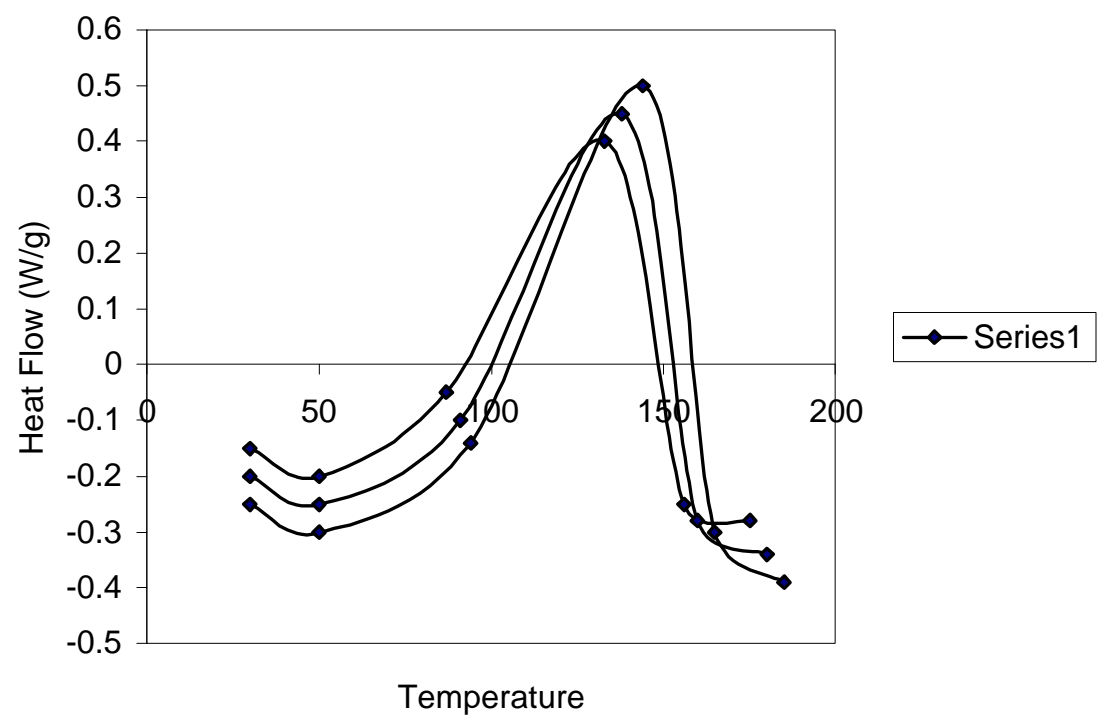

rigure - 1 


\section{Result and Discussion}

Having unsaturation in the unsaturated poly (ester-amide) resins, they were blended with Vinyl acetate monomer. As the structures of unsaturated poly (ester-amide) [14] and vinyl acetate are well established, the spectral study of the interacting blend of UPEA-VA. has not been attempted.

These UPEA-VA blends (4a-c) are viscous resins, which can be cured by adding benzoyl peroxide (BPO) as an initiator. The study of the cure was monitored on a differential scanning calorimeter. Typical DSC thermo grams are shown in Figure 1 and the data for all the resins are furnished in Table 1. Examination of the DSC thermograms indicates that each cross-linking study system exhibited a single exotherm. This indicated that cross-linking took place rather than homo polymerization. Since the polymerization catalyst is not of Zegler-Natta type bur of radical type the branced PVA would occur and which would interact with the unsaturated segment of the poly (ester-amide). Hence the glass transition temperature of PVA is not observed in the DSC thermo gram

.The unreinforced cured samples of UPEA-VA resin blends (4a-c) were also analyzed by thermogravimetric analysis (TGA). TGA data of all the cured samples are shown in the Table -2 . Examination of the TGA data reveals that the cured samples started their degradation at about $150{ }^{\circ} \mathrm{C}$ and their initial weight loss was about 3\%. This small weight loss may have been due to either insufficient curing of components used or due to the catalyst used. A weight loss of about $10 \%$ was found at $300{ }^{\circ} \mathrm{C}$. However, the rate of decomposition increased very rapidly in the range of $300{ }^{\circ} \mathrm{C}$ to $450{ }^{\circ} \mathrm{C}$ and the products were lost completely beyond $800{ }^{\circ} \mathrm{C}$

The glass fiber reinforced composites of all UPEA-VA resin blends (4a-c) were also prepared at the curing temperature obtained from the DSC scan. These composites were also analyzed for their chemical resistance and their results are furnished in Table 3.Examination of the results reveals that the composites have good resistance to common solvents like ethanol, acetone and THF. The composites were also analyzed for their mechanical and electrical properties and their results are furnished in Table 4. Examination of the results reveals that the composites have good mechanical strength. The electrical strength of all the composites is in the range of $22.0-26.0 \mathrm{kv} / \mathrm{mm}$.

Acknowledgement

We wish to thank Dr. R.M. Patel, Head of the Department for providing research facilities. The authors are grateful to Atul Ltd. Valsad, India for sanctioning the grant for the work as well as fellowship to one of the author (KKP).

\section{Reference}

1. Uerdingen W Kunstsoffe, 1993,10, 25.

2. Updegraff I H, Handbook of Plastic Materials and Technology, Wiley-Interscience, NY, pp. 817, 1990.

3. McQuarrie TS, Modern Plastic Encyclopedia, McGraw Hill, NY, 1985.

4. Lin H C, Chem. Abstr. 1994, 121(10), 697.

5. Brydson J A, Plastic Materials, 6-Edition, Butterworths, London.

6. Langston P and Zahr G E, Handbook of Plastic Materials and Technology, WileyInterscience, NY,pp. 931, 1990.

7. Gaymans R J, Bennekom V and Antoinette CM, Polym. Prep, 1997, 38 (2), 402.

8. Kargina O V, Mishustina L A, Kiselev V Y, Kabanov V A and Vyosokomol. Soedin., Ser.A. 1986, 28(6), 1139.

9. Kakimoto M, Singh Y N and Imai Y, J. Polym. Sci., Part A, Polym. Chem. 1986, 24(7), 1511.

10. $\quad$ Ellis T S, Macromol. Symp. 1996, 112, 47.

11. Zuev V V, Zhukova TI, Skorokhodov SS, Vysokomol, Soedin Ser. 1989, B 31 (6), 406.

12. Koyama E, Sanda F and Endo T, J. Polym. Sci., Part A, Polym. Chem. 1997, 35(2), 345.

13. Jiang L, Jiang Q, Xie M, Zhang J, Liu X and Cao Ji Chengdu Keji Daxue Xuebao, 1981, 2, 51.

14. $\quad$ Patel HS and Panchal K K, Int. J. Polym .(In Press).

15. Arnold H W and Searle N E, U S Patent 2467835, 1949.

16. Crivello J V, Chem Edu., 1996, 14, 159. 


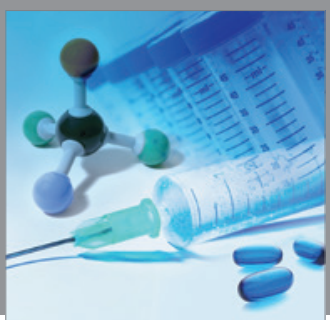

International Journal of

Medicinal Chemistry

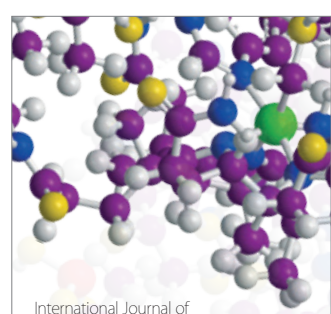

Carbohydrate Chemistry

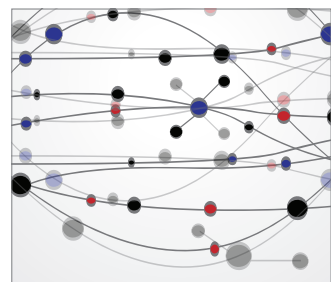

The Scientific World Journal
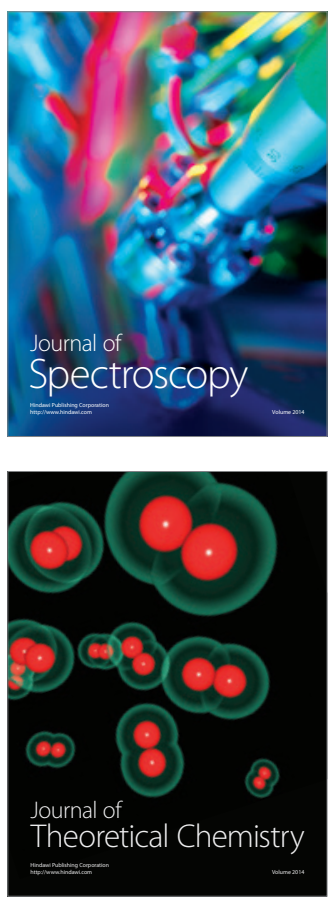
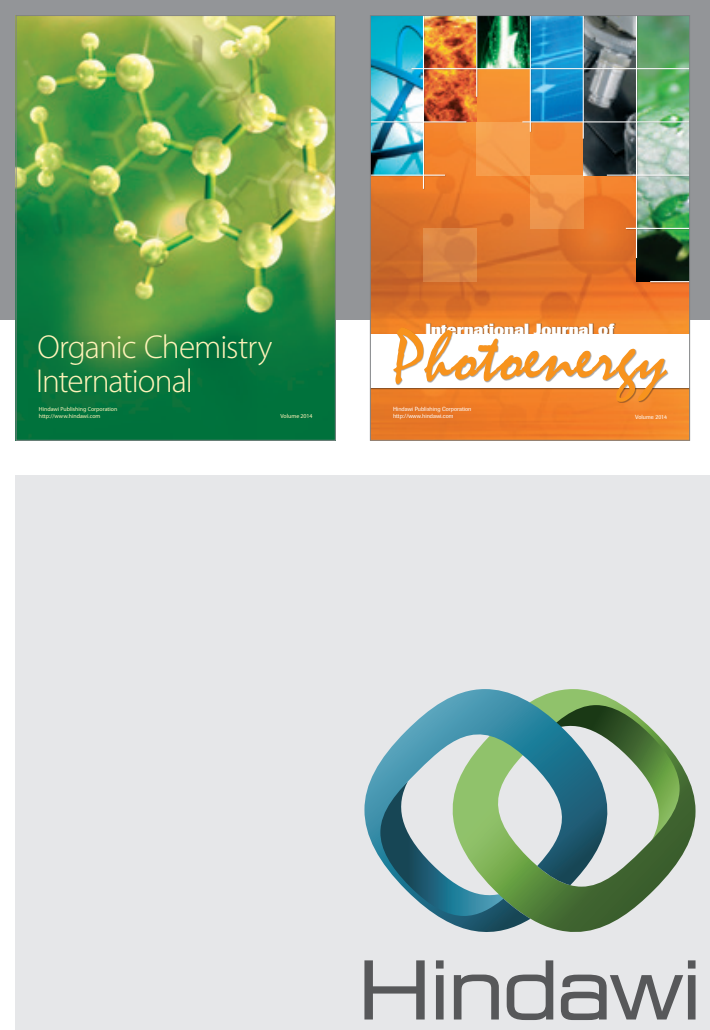

Submit your manuscripts at

http://www.hindawi.com
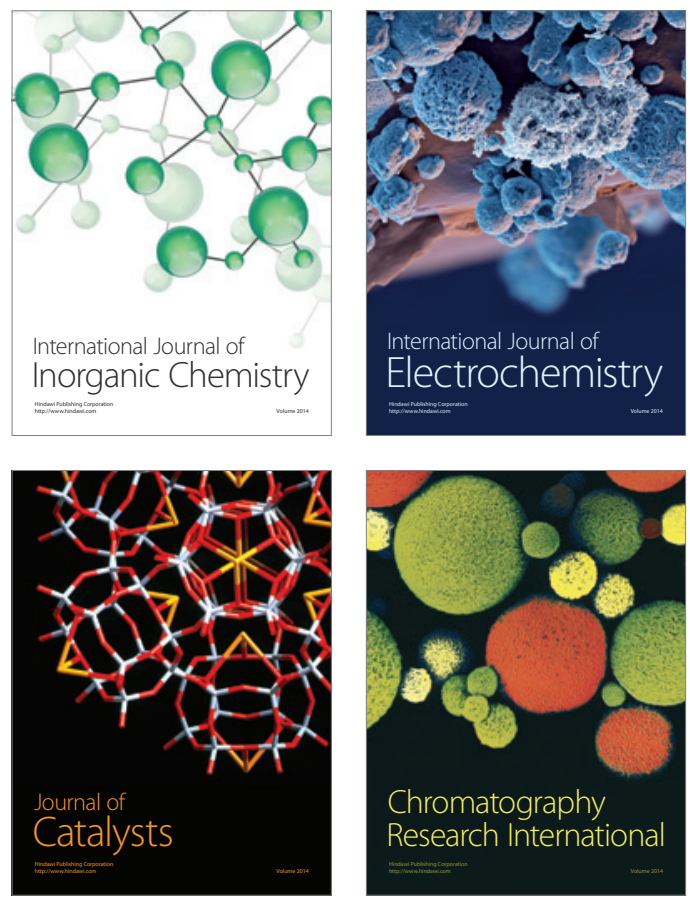
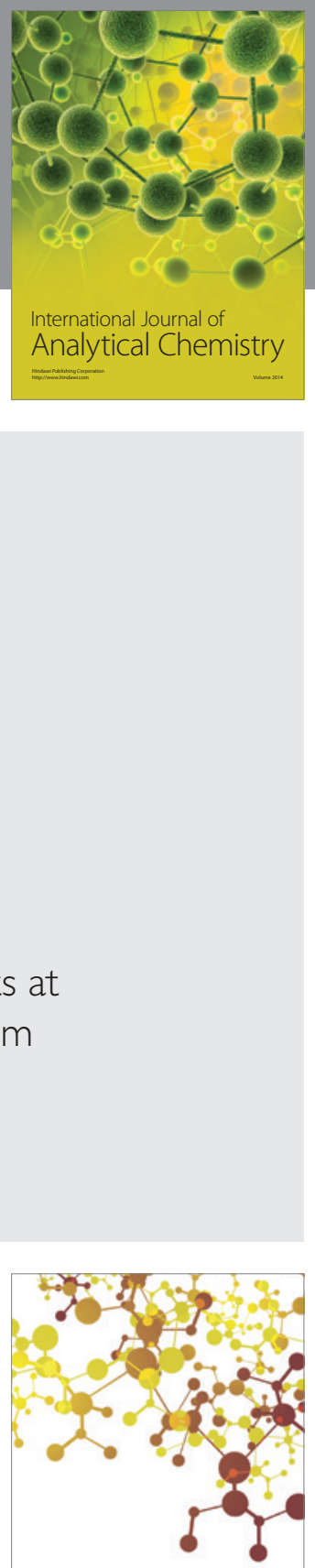

Journal of

Applied Chemistry
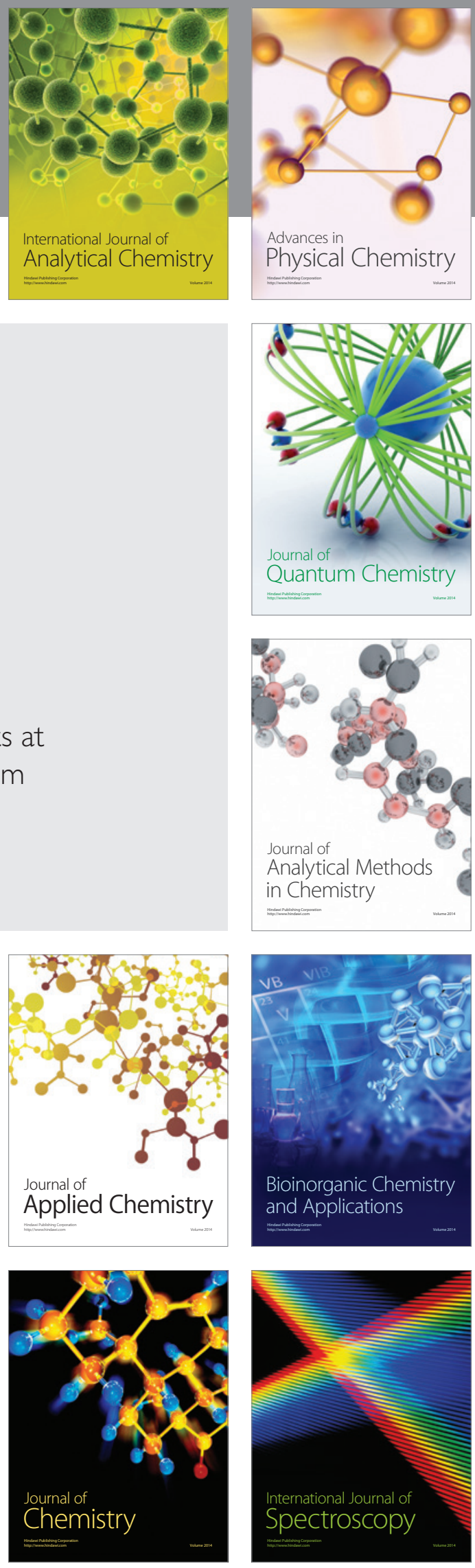